\title{
ECOLOGICAL ISSUES IN THE AGING FAMILY: INTERVENTION IMPLICATIONS \& THE FAMILY SUPPORT CYCLE
}

\author{
Joseph A. Kuypers \\ University of Manitoba \\ and \\ Vern L. Bengtson \\ University of Southern California
}

\begin{abstract}
The basic argument in this paper is that the older family, as it faces certain recurrent issues in family life and as it faces unique issues of its own aging, is placed in a highly vulnerable position. The result may be a weakening of the family's competence and an increased likelihood of family breakdown. Special attention is given to the natural changes in family dynamices as the family ages. It is argued that specific interventions aimed at promoting family competence must account for these unique features of older family life.
\end{abstract}

One of the things older people fear most is the spectre of being a "burden" to their children. One of the most sobering concerns of middle-aged individuals is the prospect of longterm care for a chronically ill parent.

The changes associated with aging present challenges to the family as well as to the individual. Confronting the challenges of aging within the family context is difficult, both for the family members themselves and for the professional seeking to help them.

There are several reasons for this. First, the problems facing an aging family are so often unexpected - and the prognoses so often appear hopeless - that the family may become immobilized. A second reason is that the crisis of an aging parent or grandparent often generates guilt among family members regarding responsibility for caretaking and support. A third reason is lack of precedent in modes of dealing with the problem. From the standpoint of the helping professional, this problem involves the ab- sence of conceptual tools and theoretical models for charting family crises in old age. In adolescence, crises are expected, parentchild conflict is anticipated, and the negotiation of crises and conflict is carried out as a matter of normal family process. No parallel expectations or normative guidelines are readily apparent for the negotiation of conflict situations in old age, nor are there any conceptual models from which the professional can chart a course of action (Kuypers and Trute, 1978; Bengtson and Treas, 1980).

This paper suggests one conceptual framework for understanding some problems and processes involving family networks and aging. We employ a heuristic systems model derived from what was originally termed the "Social Breakdown Syndrome" and applied to the etiology of mental health. The focus of this model is on social mechanisms of "labeling" operating upon and within aging families under stress. 
We feel this perspective can assist gerontologists and family practitioners in understanding successful or unsuccessful negotiation of change, as confronted by aging individuals and their families. We will focus on four psycho-social constructs important in understanding family supports and aging:

(1) negotiation of change; (2) competence;

(3) crisis; and (4) intervention and the restoration of competence.

\section{THE NEGOTIATION OF CHANGE AND CONTINUITY}

First we must consider the inevitable challenge that continually confronts the aging individual and his or her family: the negotiation of change. There are three characteristic and fundamental issues which are reflected in family negotiations around change, not just in the older family, but in younger families as well (Bengtson and Treas, 1980). These issues of family life continuously confront participants and may never achieve complete closure: autonomy versus dependency; connectedness versus separateness; and continuity versus dislocation of the family as a functional unit.

\section{Autonomy versus Dependency}

The tension between autonomy and dependency (or interdependency) can be seen at each stage of individual development. The family is often the most central arena for conflict in this area. Adolescents and parents struggle with demands to loosen family ties and authority, while still receiving and giving support. In the parents' eyes, this strain toward autonomy may imply cha$o s$. It may be a challenge to family life itself as children strive for greater freedom to determine their own fate. In the teenagers' eyes, the struggle is over personal control: the wish to define their life as independent of parental authority.

In the transitions of old age, we also can see the confrontation between autonomy and dependency: a previously independent, autonomous adult encounters sudden or gradual dependency brought on by sickness, by retirement, widowhood or other role losses. The older parent, facing uncertainty or crisis, may long for unprompted signs of concern and caretaking from their children, yet they recoil from the prospect of being dependent on children. Their children, by the same token, struggle with ambivalence: between duty to parents and duty to self, between doing too much and doing too little. The tension between autonomy and dependency requires negotiation, as both generations struggle with the normal changes of aging.

Often symbolic exchanges are the medium by which the older person attempts to maintain some degree of autonomy:

A 102-year-old man was admitted to the hospital with a broken hip. He had fallen off the ladder while attempting to clean out the gutters of his daughter's house - a seasonal task which he had carried out for years.

$\mathrm{He}$ began living with his daughter at the age of 61 , when he was recovering from a cardiac arrest and glaucoma. $\mathrm{He}$ had no financial resources and no pension. From the beginning he had insisted on doing three things: gardening, washing dinner dishes, and occasionally making the family breakfast. Carrying out these tasks, he felt, represented some exchange for the living he received from his daughter.

For 42 years he had lived with his daughter, and for 42 years he had maintained tenaciously his "role" as gardener, dishwasher, and cook despite frequent efforts of the family to "retire" him. Tremorous hands chipped the dishes as he washed them, and cataracts made the breakfasts he cooked an unending source of surprise, but until his fall he insisted on "doing his part". Recognizing the importance of these activities to his sense of justice and autonomy, his family reluctantly went along. To- 
gether, they negotiated the preservation of autonomy in the face of dependency.

\section{Connectedness and Separateness}

The negotiations of autonomy involves both generations and is frequently a source of conflict. Often it impacts on a second characteristic issue, the tension between connectedness and separateness. Some personality theorists subsume this issue under the term "individuation": the capacity to establish and maintain an identity and life style which is not unduly determined by family definition and history. Hess and Handel (1959) suggest this is the major issue in family socialization during adolescence.

But the issue of family connectedness versus individual separateness persists through later life. Following a crisis such as a stroke, adult children must struggle to sort out the reasonable and "balanced" degree of family involvement and caretaking. A less dramatic example is when a parent appears to psychologically disown a child for reasons of sexual practice, unconventional lifestyle or religion. In these instances, guilt may reign supreme as all parties uneasily confront the issue of how strongly the family will continue to hold power over each other's behaviour. Fundamental to these tensions surrounding autonomy/dependency and connectedness/separateness are issues of power, authority and control issues which persist over the entire history of a particular family's biography.

\section{Continuity versus Dislocation of the Family Over Time}

And finally, a recurrent issue facing the family as it ages concerns the fundamental question of whether that family and its interpersonal bonds will survive into the future. Change involves confrontation with the unknown and prompts concern as to what will be lost and what will remain. Often the unknown in the older family is the spectre of disintegration of family life itself (Kuypers and Trute, 1978). Hence, parents may harbor a deep-seated apprehension that family life will be lost as they have known and nurtured it when the children launch their more autonomous existence. Later in time, children may fear a loss of their own hardfought autonomy if they come closer to their elderly parents in times of need.

While the form of the issue of continuity versus dislocation may change as the family ages, we would maintain that the issue is constant. For the parents, the essential struggle may be to hold onto family as they know it, while for the child, the struggle is to loosen the bonds of family as they experience it. This is a manifestation of the "developmental stake" (Bengtson and Kuypers, 1971). Parents may strive to hold on, while children strive to loosen bonds. Faced with a family transition (expectable or otherwise) the question of the family's very survival, as defined in the past, is at stake.

\section{Psychological Well-Being and Family Ties}

The relationship between family life and mental health is implied in each of these tensions. We have thus far argued that the normal course of family life involves negotiation between generations and, furthermore, that the negotiation often embodies conflict. Such conflict is centered often on the nor$\mathrm{mal}$ and inevitable - if often unanticipated - tension that surrounds recurrent issues of autonomy, connectedness and survival. In making our argument, we have left unattended that question of how family involvement in late life relates to the mental health of its members.

It is often assumed that family relations influence the well-being of older family members. After all, families are or should be a source of assistance. In the public mind, the relationship between family life and the mental health of the aged is unequivocal. Many assume that close intergenerational ties promote happiness, that a close-knit family will care for its elder 
members, and that all parties should feel satisfied in the expression of their "filial maturity".

There is some foundation for these assumptions. To be sure, many if not most older people derive satisfaction from interaction with their kin (Shanas, 1976; Bengtson and Treas, 1980). But there are other elderly individuals who have no families. There are others who have families who are indifferent to them. And in still other families, children may be a source of continuing shame and discomfort to the aging parent.

Despite our cultural bias toward cordial and intimate family life, there is surprisingly little explicit evidence from surveys that older people without supportive kin networks are at a psychological disadvantage (Bengtson and Treas, 1980). Indeed, several surveys suggest that intense interaction need not lead to greater happiness for older family members. For example, Kerckhoff's (1966) study of retired couples found that husbands and wives who lived close to their offspring had lower morale than those who lived farther away. In a large national survey of Americans 58 to 63, married men living with kin were less likely to report themselves "happy" than were those who shared housing only with a wife (Murray, 1976). In a South Carolina survey of older widows, Arling (1976) reported no association between morale and contact with kin, especially contact with children. Contact with friends and neighbors, on the other hand, did serve to reduce loneliness while increasing feelings of usefulness.

Given these data, as well as our own personal observation of the intense ambivalences encountered by all family members as they adapt to their aging family, we must caution against a simple notion that "more" family is necessarily "better", or that "closer is happier". This notion is too facile. The dynamics of aging families are complex, the issues they face are fundamental, and any image of what is "good" or "happy" older family must be tempered by the immense variability displayed among families.

We now turn to the dynamics of the older family as it ages in hopes that this investigation will help tune the clinician's eye to possible differences between older and younger families. Thus far we have implied that the older and younger family face similar concerns and issues.

But the older family is different, in many respects, from the younger family. These differences are crucial to explore, for they imply needed changes in family intervention theory. The contrasts help explain unique dilemmas facing participation in the aging family. And the differences point the researcher to important areas of inquiry.

There are several important ways in which the family of an older person facing crisis is different from the family in which the problem involves a younger member. $\mathrm{A}$ first contrast concerns the natural decreasing involvement with the family-of-orientation throughout life. As the family ages and as each of its members find and establish their adult status, they do so with a shared agreement: " that the intensity of day to day involvement, of doing for and being done for, of being 'on call' and available to help, as well as of the desirability of shared family living itself all follow a natural family cycle of waning intensity" (Kuypers and Trute, 1978).

If a crisis emerges in a young family, it does so in the context of relatively high involvement and interdependency. In the older family, the bonds are substantially looser and insofar as a crisis may draw members together, this will prompt resistance and ambivalence.

Second, as the family age, there occurs a diversification of loyalty. Bondedness to one's parents is expected to decrease with adolescence and certainly into young adulthood. As overt and "invisible" loyalties loosen in the family-of-orientation, they transform and extend to new commitments. And if a crisis in the older family emerges, often its companion is intense conflict; over financial obligations, time commitment, 
duty and responsibility. The natural diversification process is sometimes rudely interrupted by an immediate and unexpected call to old loyalties.

Third, the nature of familial exchange is often quite different in older families. In young families, for the most part, "the vectors of care giving are one way - parents caring until the care is not needed and parents taking responsibility for the myriad of decisions and choices around that function." (Kuypers and Trute, 1978). With time these patterns loosen and sometimes, with crises old age, a reversal is required. Often older families find this reversal difficult to negotiate, as is exemplified in much of the literature on older family life which speaks to the turmoil around defining the "burden bearer", sibling conflict over responsibility of an older parent, and guilt over failure to serve well.

A forth contrast in the problem-solving style of older and younger families involves a reaction of the family to the limits imposed by the first three; that is, the greater use of denial as a coping measure. Wtih decreasing involvement, diversification of loyalties and resistance to altering old patterns of exchange, older families are likely to delay and avoid a quick response to an emerging crisis. Furthermore, because of the dismal subjective meaning often attached to many problems of aging (they are often seen as irreversible, negative, and unresolvable), the older family is more likely than the younger family to experience immobiliation and confusion as it is called together in emergency.

A fifth difference between older and younger families dealing with crises involves the power of negative history as a problem-solving unit. The older family has accumulated more historical baggage which they can carry into crisis work. An older family has to deal with two, three and perhaps four decades of unresolved intergenerational tension. And it seems in the nature of passing time that the small issues lose importance while the large issues remain in place, poised for re-emergence.

To fully understand the older family, we would claim, one needs to study its uniqueness and special form. And this inquiry must lead to an appreciation of the great diversity between older families.

Many families face crises of aging. And many deal with the difficulties of aging very adaptively and some not. Why is it that some individuals appear to age more successfully than others?

\section{COMPETENCE AND BREAKDOWN}

In charting the poorly understood dynamics of aging families, a second major construct which we find useful is that of competence and its opposite, breakdown. "Competence" is a useful description of the behavioural goal or ideal in negotiating the transitions of aging. Sometimes called mental health, sometimes called adaptation, it is a practical conceptual tool for describing successful dynamics of the aging family,

\section{Three Faces of Competence}

Competence as it relates to aging can be defined in terms of three separate dimensions, as we have done in an earlier paper (Kuypers and Bengtson, 1973). The first is adequate role performance. Competence in a sociological sense involves doing what the social context sees as appropriate, and carrying out in normatively acceptable ways, the social positions one occupies. A second dimension of competence is more psychological: the capacity to adapt or to cope in response to new or unusual stimuli. Yet a third dimension of competence is phenomenological, involving experienced mastery: the sense that one has some degree of control or power over events or changes in one's world. Competence must be seen in all three of these facets: as adequate social performance, as the psychological capacity to adapt and cope, and as the experience of mastery or efficacy over one's fate and surrounding environment. 


\section{Labeling and Psycho-Social Incompetence}

An individual's competence may be assaulted in each of these dimensions by changes associated with aging. In an earlier paper, we emphasized the concept of the "Social Breakdown Cycle" to help understand how this massive assault might occur. This is represented in Figure 1, which shows a six-step malignant spiral of breakdown, dependency and increasing incompetence.

The steps of the cycle are indicated by numbered circles connected by negative valences (arrows). The boxes represent inputs to the cycle which exacerbate the vicious spiral of incompetence. These inputs are from the social environment of the older person. Some are from the broader societal context, others from the immediate interpersonal environment of family, friends, or professionals.

The cycle begins (step number one) with vulnerability, wherein circumstances combine to increase the susceptibility of the older individual facing crisis or loss. This vulnerability may arise from several sources (input A): because of suddenly decreased resources (lack of health, economic problems following retirement); or because of "ageism", societal stereotyping about the aged or discrimination against them; or because of societal values which emphasize productivity at the expense of respect for eldership. These leave the older individual vulnerable, at risk in terms of his capacity to adequately perform roles, to adapt to new stimuli, or to have a sense of mastery. This vulnerability becomes acute in the presence of a crisis event, such as sudden illness, or from social losses, such as widowhood or retirement. Note that these are normal, expectable changes in the aging individual's social world: challenges to his or her continuity of psychosocial competence.

The older person is then susceptible to step number two, dependence on external definitions of the situation. In new contexts with new stimuli, one frequently distrusts past patterns of behaviour. The older individual, in the midst of a transition involving retirement, the empty nest, widowhood. chronic illness or relocation, may be particularly dependent on external definitions of reality - since former experiences may be judged inadequate. Input B to this stage includes doubts expressed by others - of by the individual - concerning the adequacy of past coping strategies and resources. A related set of inputs reflects ambiguous norms or expectations concerning behavjour in this new and vulnerable situation.

This can lead, in turn, to step number three, social labeling of the older person as incompetent and incapable of caring for oneself. The older individual receives the attribution of helplessness and of inadequacy from his or her interpersonal environment (input C). This leads to step four, induced dependency. Others begin to do for the older individual what he or she had previously done for himself. In a new environment, such as a nursing home, this step is particularly apparent. The older person becomes induced into a "sick role" by the surrounding environment (input, D) and is expected to act accordingly.

The fifth step of the cycle involved atrophy of previous skills for competence and independence. The external system may encourage this "learned helplessness" (input E). This leads to the sixth stage, internalization of the new and now dependent identity. The end is self-labeling as incompetent and the "social breakdown" can be said to have occurred. Yet this only leads to another round of the spiral, for the new identification creates yet more vulnerability (step one again) and the cycle continues.

This vicious spiral, originally developed to describe the development of "mental illness", is here applied to older individuals made vulernable by fundamental developmental changes. It is a vicious cycle of in competence, leading to a defined breakdown in terms of previous role performance, in terms of coping ability, and 


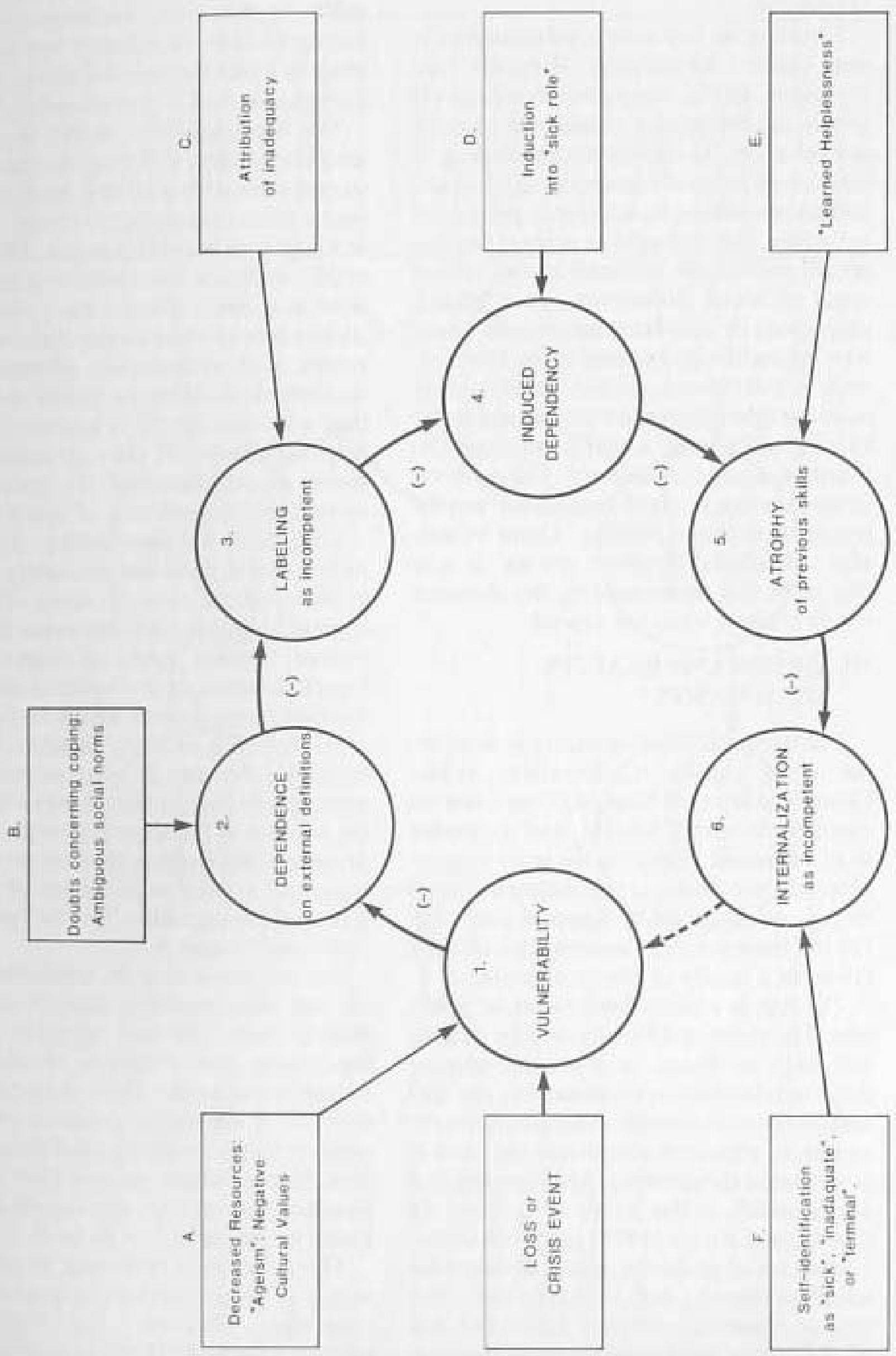


in terms of a sense of mastery or confidence.

Note that the key issue is vulnerability. In our earlier formulation (Kuypers and Bengtson, 1973), we argued that most old people in contemporary industrial societies are vulnerable to incompetence labeling because of reduced resources, ageism, and societal emphases on economic productivity values. But it should be pointed out that not all individuals succumb to the vicious spiral of Social Breakdown, even when a crisis event or significant loss occurs. Many who are vulnerable because of one role loss, such as widowhood, are sufficiently able to continuc other role performances and to use existing coping or adaptive strategies to maintain a sense of mastery. These are effective enough to avoid dependence and the power of negative labeling. Other vulnerable individuals, however, are not. It is at this point that understanding the elements which create a crisis are crucial.

\section{CRISIS AND REALITY DISTORTION}

The third construct necessary to describe the aging family is, therefore, crisis. Changes in later life become crises when the event is perceived, labeled, and responded to as a dramatic change in the level of competence. According to contemporary crisis theory, as described by Kuypers and Trute (1978), there are three issues which define a crisis for a family or for an individual.

The first is a hazardous event or problem. The event or difficulty may be defined variously as illness or economic loss or death or relocation or accident, etc. The second component of crisis is the subjective response of witnesses who define the hazardous event as threatening. The meaning that actors attach to the event is crucial. As Spector and Kituse (1973) point out in discussing social problems, not all disasters are social problems, not all misfortunes are seen as requiring collective action and, not all difficulties are perceived as amenable to amelioration. The third feature of crisis is an inability to respond with previous coping skills. In this case, the issue of adequate coping focuses on whether the family can work as a unit through the crisis, where the aging individual is precariously placed.

Our basic argument in this paper is that the older family, as it faces the recurrent is. sues of family life and as it faces the unique issues of its own aging members, is placed in a highly vulnerable position. This vulnerability increases the crisis elements in their work as a family. Furthermore, when a crisis involves an older family member (with a stroke, or in widowhood), adaptation is often more difficult for the family to deal with than when the family is younger. Figure 2 helps depict some of our argument. Figure 2 shows an adaptation of the social break. down spiral to problems of aging families.

First, there is vulnerability: susceptibility to a shared view that the family is unable to cope with the crises of aging. This is the context in which the crisis event is quickly viewed. Several inputs (as diagrammed in Figure 2) increase the vulnerability of the family to incompetent action in the face of crisis involving an older member. First, the crisis may be seen as more serious or less amenable to change than it may objectively be, because of the unprecedented degree of severity of the event or because problems of aging are viewed as instances of progres sive, hopeless decline. This is "perceptual distortion" (input A).

Second, there may be conflicting loyalties and roles regarding generational membership (input B) and apparent conflicts concerning how members should be involved in that crisis. There is also (input $\mathrm{C}$ ) the lack of normative guidance in dealing with problems involving aged family mernbers. In our culture we lack clear expectations concerning what one should do with it parent or parent-in-law in need.

There may be a resistance to greater intensity of involvement on the part of middle generation children. The "generation squeeze" (input D) is felt by many childrent who, with limited time, resources, and al. 
ECOLOGICAL ISSUES IN THE AGING FAMILY

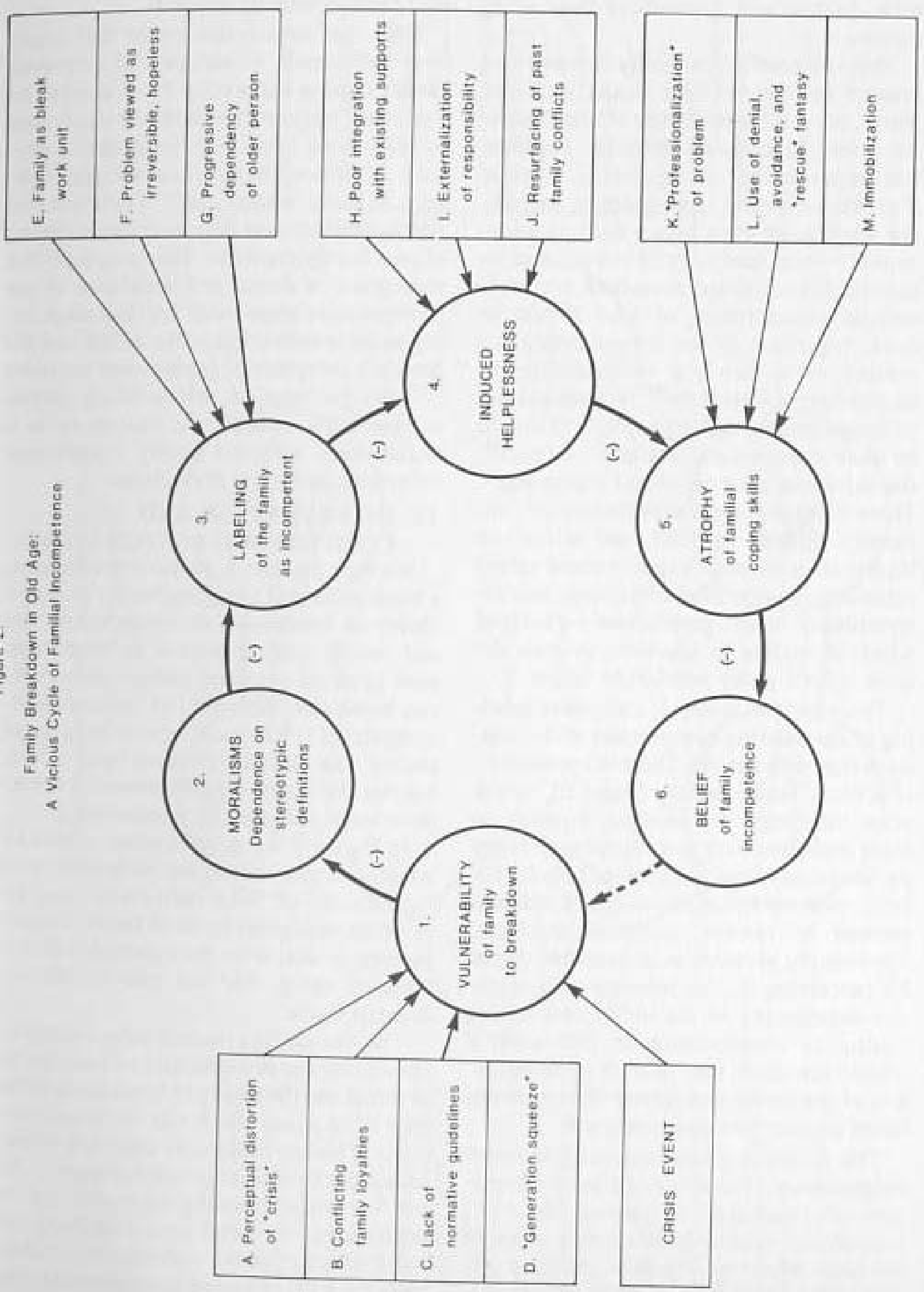


ternatives, are caught between demands of their children and demands of their aging parents.

This vulnerability of family competence, created by the multiple inputs indicated above, often is characteristic of many otherwise well functioning extended families. But the presence of a stress event - such as a stroke, or mental incompetence suggesting senility, or even losses such as widowhood - may lead (step 2) to a reliance on external prescriptions: moralistic and stereotypic prescriptions of what should be done, regardless of the unique conditions leading to a family's vulnerability. "I should help my mother." "We should not let her go into the nursing home." "I should be more attentive and available. After all, she did so much for me when I was young!" These overgeneralized expectations are, obviously, difficult to fulfill, and failure is a logical consequence. Vague societal values regarding loyalty, filial obligation, and responsibility across generations - each of which is unclear in specifics, provide the context for a guilty reaction to failure.

This may lead to step 3 , a negative labeling of the existing competence of the family to deal with a crisis. There is a possibility of a bleak family history (input E), where prior difficulties in working together to solve problems were met. In the past, many problems may have been solved only by default, wherein the leave-taking of children seemed to resolve persistent conflicts. Viewing the problem as irreversible (input F), perceiving it as an instance of progressive dependency of the older person, and fearing an overextension of the family's limited resources may prompt immobilization of the family and further their growing belief in their own incompetence.

The fourth step can be termed induced helplessness. There may be poor integration with existing social supports (input $\mathrm{H}$ ). As is almost invariably the case, families do not know what agencies exist, public or private, from which help might be sought. Alternatively, there may be externalization of the problem (input $\mathrm{I}$ ) and the resurfacing of past family conflicts (input J).

Fifth, the immobilization of the family eventually leads to atrophy of previous family coping skills (step 5). A need to be "rescued" may emerge as the family comes to rely more frantically on external supports. "We don't have to deal with the problem. A social worker can!" There may be sibling conflict over duty, and a resurfacing of past family conflicts. This may lead to a resurgence of denial and avoidance of the problem once again, with the final stage being an internalization of the belief that the family is incapable of coping with the older person's problem. A self-fulfilling prophecy has been initiated; the vicious cycle is begun anew with the family competence vulnerable to further breakdown.

\section{INTERVENTION AND \\ COMPETENCE RESTORATION}

We have presented, for heuristic reasons, a bleak picture of the aging family's vulnerability to breakdown in competence. But our fourth point concerns intervention: how professionals and caring individuals can break into this spiral of increasing incompetence. (We do not mean to suggest, of course, that all older families break down, but that, for many, the conditions for breakdown exist and must be understood.)

In Figure 3 we suggest some means by which one can reduce the vulnerability of families and of older individuals, and reverse the malignant cycle of family incompetence to deal with the expectable transitions of aging. We call this the Family Support Cycle.

The first step is to reduce vulnerability decreasing the susceptibility of both the individual and the family to breakdown in the face of an event which can be viewed as a crisis. This can be done by attending to various input factors indicated in Figure 3. Input $A$ is time-consuming but crucial: for the professional to spend time clarifying the event with the family - discussing realistically the level of probable impairment after a stroke, for example, or the progression of 
CANADIAN JOURNAL OF COMMUNTTY MENTAL HEALTH

\begin{tabular}{|c|c|c|c|c|}
\hline 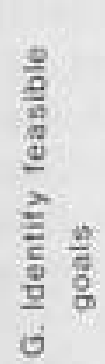 & 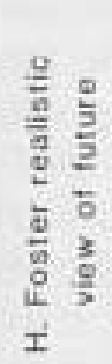 & 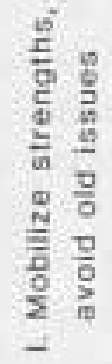 & 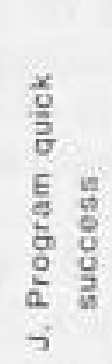 & 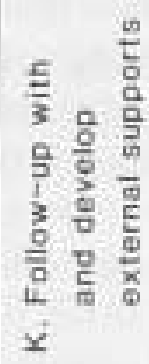 \\
\hline
\end{tabular}

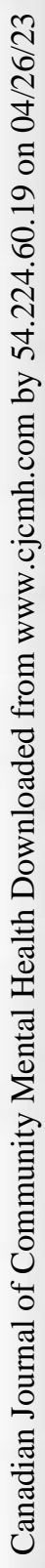
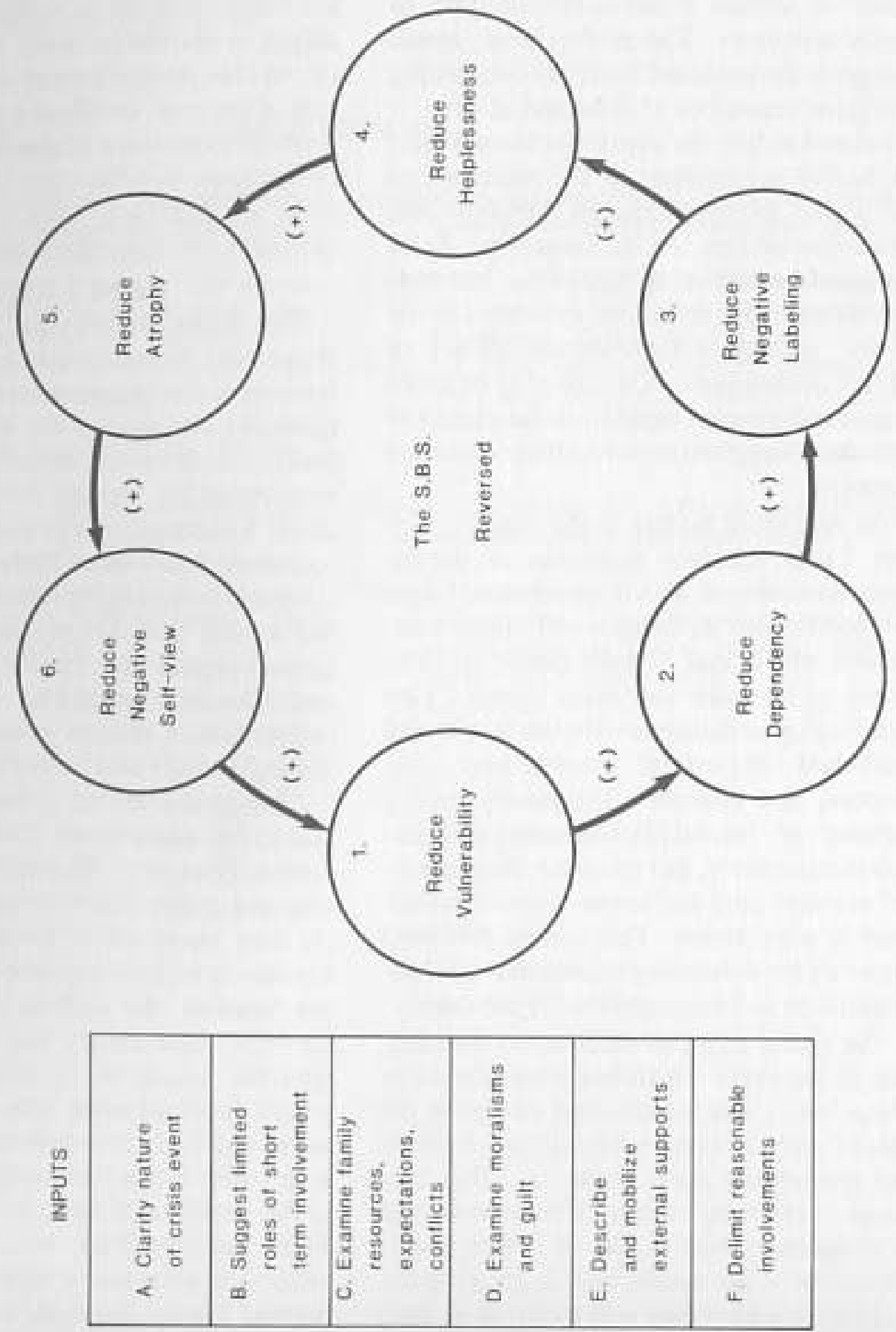
Alzheimer's disease. Most family members operate in a total information vacuum as they confront a disabling event. The professional must offer clear guidelines of support as an informational means of redefining the crisis.

Another input (input B) by the professional involves discussion of the acceptable and limited involvement on the part of family members. The family - and the professional - should avoid over-extension of family resources. The professional should recognize the personal anxieties concerning overtaxed resources of time and effort.

Related to his, the counselor should alert the family participants to the existence of competing intergenerational demands and their expectability. At the same time, he or she should avoid being lured into "correcting" historically stabilized dynamics in the family, with their own unique history of roles and coalitions. A useful ploy to avoid over-involvement (input E) is the clear and repeated suggestion of other external supports.

An important feature in the Family Support Cycle involves reduction of dependence on external and inappropriate labels - specifically, moralisms and cliche obligations which lead to guilt (input D). The helper or therapist can assist (input C) by fostering open dialogue with the family and individual regarding expectations, resources, and conflicts. Frequently family members are fearful of confronting such expectations openly, but often the dialogue itself releases guilt and lowers fears of unreasonable expectation. This can be followed (input $\mathrm{F}$ ) by delimiting reasonable interdependencies and expectations for the family.

The Cycle requires a collective redefinition of the event which has been labeled as "hopeless". The professional can assist the older family at risk by identifying feasible and appropriate goals (input G). This may mean 1) resisting efforts of those involved to exaggerate (out of fear or helplessness) the extent of the crisis, and 2) grieving the real losses which they will confront as they begin to accept the limits to recovery. It is necessary (input $\mathrm{H}$ ) to foster an honest, realistic appraisal of future developments improvement and decrement.

The Family Support Cycle calls for mobilization of realistic coping skills. This will reduce the atrophy of skills apparent prior to the crisis, and reduce dependence on external definitions. The professional should focus on strengths (input I), emphasizing what the family can do as contrasted with what might or should be done. It may be useful (input J) to program some quick demonstration of success, to affirm a positive (and delimited) experience of mastery. It is certainly necessary to follow this up by demonstrations of interface with external support networks, realistically identified (input K).

\section{CONCLUSION}

This paper has presented one conceptual framework for understanding both the problems and the processes involving family networks and aging. We have employed a heuristic systems model derived from what was originally termed the "Social Breakdown Syndrome". The focus has been on social mechanisms of "labeling" operating upon and within aging families under stress. We argued that this perspective can assist gerontologists and family practitioners in understanding successful or unsuccessful negotiation of change as confronted by aging individuals and their families.

Change is a normal consequence of aging and competence is the desired outcome of normal changing. We suggested that recurrent and unique issues facing the older family may reach crisis levels because older families are more vulnerable than are younger families. We explored various reasons for this vulnerability and we described a possible negative cycle of breakdown. where incompetence was likely. We also suggested that intervention might take place at any step of this vicious spiral. By looking at the family as a unit, and recognizing its limits and capacities, we see hope for intervention in what many regard as a relatively hopless family situation: crises in old age. 


\section{RÉSUMÉ}

L'affirmation principale de cet article est la suivante: la famille qui veillit. face à certains problèmes récurrents de la vie familiale et au problème spécifique de son veillissement, se trouve dans une situation hautement vulnérable. Le résultat de cette situation pourrait ètre un affaiblissement des compétences de la famille et un accroissement de la probabilité d'un effondrement familial. On accorde une attention spéciale aux changements naturels de la dynamique familiale au moment ou la famille veillit. On prétend que les interventions destinées à promouvoir les compétences familiales doivent tenir compte de ces caractéristiques specifiques de la famille veillissante.

\section{REFERENCES}

Arling, G. 1976. The elderly widow and her family, neighbors and frietnds. Journal of Marriage and the Family, 38, 757-768.

Bengtson, V.L. and Kuypers, J.A. 1971. Generational differences and the developmental stake. Aging and Human Development, 2, 249.260.

Bengtson, V.L. and Treas, J. 1980. The chunging family of mental health and aging. In J.E. Birren and R.B. Sloane (eds.), Handbook of Mental Health and Aging. Englewood Cliffs, NJ: Prentice-Hall.

Hess, R.D. and Handel, G. 1959. Fanily Worlds. Chieago: University of Chicago Press.

Kerckhoff, A, 1966. Family patterns and morale in retirement. In L.H. Simpson and J.C. McKinney (eds.), Social Aspects of Aging. Durham, NC: Duke University Press:
Kuypers, J.A. and Bengtson, V.L. 1973. Social breakdown and competence. Human Development. 16. 181-201.

Kuypers, J.A. and Trute, B. 1978. The older family as the locus of crisis intervention. The Family Coondinator, 27, Oct., 405-411.

Murray, J. 1976. Family structure in preretirement years. In M. Irelan, et al., Almost 65:-Baseline Date from the Retirement History Study. Washington, DC: Government Printing Office, 82. 101.

Shanas, E, and Maddox, G.L. 1976. Aging, health and the organization of older people. Journal of Social Issues, 30, 79-92.

Spector, M. and Kituse, J, 1973, Social Problems: A reformulation. Social Problems, 21, 145-149; and Constructing Social Problems. Menlo Park, CA: Cummings, 1977. 